\title{
EFEKTIVITAS PENGGUNAAN MODAL KERJA DALAM UPAYA MENINGKATKAN LIKUIDITAS MASING-MASING UNIT USAHA KSU KARYA NUGRAHA JAYA KABUPATEN KUNINGAN
}

\author{
Eka Setiajatnika \\ Institut Manajemen Koperasi Indonesia \\ ekasetiajatnika@ikopin.ac.id \\ Muhamad Ardi Nupi Hasyim \\ Institut Manajemen Koperasi Indonesia \\ ardi.nupi@yahoo.com2 \\ Dian Pitriyani \\ Institut Manajemen Koperasi Indonesia \\ dianpitriyani.id@gmail.com3
}

\begin{abstract}
Abstrak - Modal kerja yang baik adalah modal yang dikelola secara efektif untuk dapat mencapai target yang diharapkan. Efektivitas modal kerja dapat diukur melalui perputaran modal kerja masing-masing unit usaha untuk mengetahui tingkat efektivitasnya. Selain itu likuiditas tidak boleh terlalu rendah agar memiliki posisi keuangan yang kuat dan tidak boleh terlalu tinggi agar tidak ada dana menganggur. Analisis rasio likuiditas terhadap modal kerja digunakan untuk melihat efektivitas penggunaan modal kerja dan dapat menggambarkan posisi keuangan jangka pendek. Upaya meningkatkan likuiditas dapat dilakukan dengan cara meningkatkan efektivitas penggunaan modal kerja melalui penyisihan dana cadangan yang ditanamkan pada aktiva lancar, meningkatkan jumlah simpanan wajib anggota untuk menambah modal kerja dalam menutup kerugian usaha, serta mengikuti program LPDB KUMKM untuk memperoleh dana hibah maupun pinjaman dengan suku bunga rendah yang dapat menambah modal kerja.
\end{abstract}

\section{Kata Kunci: Efektivitas, Modal Kerja, Likuiditas}

Abstract - Good working capital is capital that is managed effectively to achieve the expected target. The effectiveness of working capital can be measured through the working capital turnover of each business unit to determine the level of effectiveness. In addition, liquidity should not be too low in order to have a strong financial position and should not be too high so that there are no idle funds. The analysis of the ratio of liquidity to working capital is used to see the effectiveness of the use of working capital and can describe the short-term financial position. Then efforts to increase liquidity can be done by increasing the effectiveness of the use of working capital by increasing working capital turnover which will have an impact on increasing the allowance for reserve funds invested in current assets, increase the productivity of 
EFEKTIVITAS PENGGUNAAN MODAL KERJA DALAM UPAYA MENINGKATKAN LIKUIDITAS MASING-MASING UNIT USAHA KSU KARYA NUGRAHA JAYA KABUPATEN KUNINGAN

milk production which will increase the number of mandatory savings for members to increase working capital to cover business losses, and participate in the LPDB $K U M K M$ program to obtain grants and loans with low interest rates that can increase working capital.

\section{Keywords: Effectivity, Working Capital, Liquidity}

\section{PENDAHULUAN}

\section{Latar Belakang}

KSU Karya Nugraha Jaya Kab. Kuningan yang berawal dari kelompok peternak sapi, usaha yang dijalankannya terus bertumbuh dari hanya dapat menghasilkan susu sapi sebanyak 195 liter/hari dari 15 orang peternak sapi pada tahun 1994. Semakin berkembang dalam waktu satu bulan anggota kelompok peternak bertambah menjadi 35 orang yang dapat menghasilkan produksi susu sebanyak 300 liter/hari. Perkembangan terus terjadi hingga tahun 1997 anggota bertambah menjadi 200 orang dengan produksi susu mencapai 3000 liter/hari.

Melihat keberhasilan kelompok peternak sapi perah karya nugraha jaya yang terus berkembang ini menjadikan perubahan status pada tanggal 01 September tahun 1998 menjadi badan usaha koperasi yang diberi nama 'Koperasi Serba Usaha Karya Nugraha Jaya' dengan badan hukum Nomor : 01/BH/KDK/10-18/IX/1998.

Koperasi Serba Usaha Karya Nugraha Jaya yang beralamatkan di Jl. Cipari-Gunungkeling, Kelurahan Cipari, Kecamatan Cigugur, Kabupaten Kuningan, Provinsi Jawa Barat 45552. Memiliki beberapa unit usaha yaitu unit usaha produksi susu dan unit usaha pakan barang, unit usaha peternakan, unit usaha simpan pinjam.

Demikian

menjalankan kegiatan usahanya memiliki kesamaan tujuan dengan perusahaan yang umumnya bertujuan untuk memaksimalkan/meningkatkan asset secara optimal melalui pemanfaatan potensi yang dimilikinya dengan baik, terutama dalam pengelolaan modal kerja (Lukman Syamsuddin, 2004:10). Pemanfaatan pengelolaan modal kerja dengan baik penting karena modal kerja merupakan faktor utama bagi perusahaan dalam menggerakkan operasional usahanya di mana separuh dari aktiva perusahaan yakni aktiva lancar merupakan modal kerja perusahaan. Salah satu faktor dalam menunjang pencapaian hasil usaha yang optimal terletak pada pengelolaan modal kerja yang efektif.

Menurut Lukman Syamsuddin (2004:201) modal kerja merupakan salah satu aspek penting dari keseluruhan manajemen pembelanjaan perusahaan. Apabila perusahaan tidak dapat mempertahankan tingkat 'modal kerja yang memuaskan' maka kemungkinan perusahaan tidak mampu membayar kewajiban-kewajiban jangka pendek yang telah jatuh tempo. Dalam hal ini aktiva lancar harus cukup besar untuk dapat menutupi hutang suatu perusahaan agar dapat tercipta keamanan keuangan serta kemampuan membayar yang baik. Kemampuan perusahaan dalam membayar kewajiban-kewajiban ini dinamakan likuiditas. Menurut Agus Harjito dan Martono (2011:53) mengungkapkan rasio likuiditas merupakan rasio yang menunjukkan hubungan antara kas perusahaan dan aktiva lancar lainnya dengan hutang lancar. 
Menurut penjelasan dalam Arrin Prastiwi Widiarti Putri, Moch. Dzukirom AR, dan Muhammad Saifi, (2016:55) menjelaskan analisis rasio likuiditas sebagai berikut :

"Analisis rasio likuiditas terhadap modal kerja perusahaan sangat diperlukan untuk menginterpretasikan posisi keuangan jangka pendek dari perusahaan tersebut serta dapat digunakan untuk melihat efisiensi dan efektivitas penggunaan modal kerja di dalam perusahaan".

Berdasarkan pengertian di atas dapat disimpulkan bahwa efektivitas penggunaan modal kerja berhubungan dengan likuiditas. $\mathrm{Di}$ mana tingkat likuiditas sangat penting untuk dapat melihat efektivitas penggunaan modal kerja koperasi sudah dapat dikatakan efektif atau belum. Begitu juga sebaliknya efektivitas modal kerja yang baik maka akan berdampak baik pula pada posisi keuangan jangka pendek koperasi, yang di mana apabila penggunaan modal kerja efektif dengan perputaran modal kerja yang tinggi maka akan menghasilkan tingkat keuntungan yang tinggi sehingga keuntungan yang dapat dicadangkan untuk modal kerja yang tertanam aktiva lancar.

\section{Rumusan Masalah, Manfaat dan Tujuan Penelitian \\ Rumusan Masalah :}

1. Bagaimana efektivitas penggunaan modal kerja masing-masing unit usaha dilihat dari perputaran modal kerja pada KSU Karya Nugraha Jaya Kabupaten Kuningan.

2. Bagaimana Likuiditas masingmasing unit usaha pada KSU Karya Nugraha Jaya Kabupaten Kuningan.

3. Bagaimana pencadangan dana untuk modal kerja masing-masing unit usaha di KSU Karya Nugraha Jaya Kabupaten Kuningan.
4. Bagaimana upaya untuk meningkatkan likuiditas masingmasing unit usaha melalui efektivitas penggunaan modal kerja pada KSU Karya Nugraha Jaya Kabupaten Kuningan.

\section{Kegunaan :}

Untuk dapat memberikan masukan kepada semua pihak yang berkaitan dengan koperasi dalam rangka menjawab permasalahan yang ada untuk kemajuan koperasi dalam pengembangan usahanya.

\section{Tujuan Penelitian:}

Adapun tujuan yang ingin diperoleh dari penelitian ini adalah untuk mengetahui :

1. Efektivitas penggunaan modal kerja masing-masing unit usaha dilihat dari perputaran modal kerja pada KSU Karya Nugraha Jaya Kabupaten Kuningan.

2. Likuiditas masing-masing unit usaha pada KSU Karya Nugraha Jaya Kabupaten Kuningan.

3. Pencadangan dana untuk modal kerja masing-masing unit usaha di KSU Karya Nugraha Jaya Kabupaten Kuningan.

4. Upaya untuk meningkatkan likuiditas masing-masing unit usaha melalui efektivitas penggunaan modal kerja pada KSU Karya Nugraha Jaya Kabupaten Kuningan.

\section{Tinjauan Pustaka}

Koperasi memiliki perbedaan dengan badan usaha lain, di mana perbedaan ini merupakan karakter koperasi yang tercermin dalam jadi diri koperasi. Jati diri koperasi merupakan kesatuan dari Definisi Koperasi, Nilainilai Koperasi, dan Prinsip-prinsip Koperasi. 
Menurut International Co-operative Alliance (ICA) menjelaskan koperasi adalah perkumpulan otonom dari orangorang yang bersatu secara sukarela untuk memenuhi kebutuhan-kebutuhan aspirasi ekonomi, sosial, budaya secara bersama melalui perusahaan yang mereka miliki dan dikendalikan bersama secara demokratis.

Menurut Agus Harjito dan Martono (2011:4) menjelaskan manajemen keuangan adalah segala aktivitas perusahaan yang berhubungan dengan bagaimana memperoleh dana, menggunakan dana, dan mengelola aset sesuai tujuan perusahaan secara menyeluruh.

Berdasarkan penjelasan tersebut dapat dipahami bahwa tujuan manajemen keuangan adalah untuk memaksimumkan keuntungan perusahaan yang tentunya akan meningkatkan kemakmuran pemilik atau pemegang saham. Aplikasinya dalam koperasi adalah dalam memaksimumkan sisa hasil usaha (SHU) yang didapatkan koperasi dari kegiatan usahanya untuk kemakmuran koperasi dan anggota.

Setiap badan usaha perusahaan maupun koperasi dalam menjalankan kegiatan usahanya membutuhkan modal kerja untuk membelanjai operasionalnya sehari-hari, contohnya seperti membeli bahan baku, membayar upah dan gaji, membayar rekening listrik, membayar biaya transportasi, membayar hutang dan lainnya.

Menurut Bambang Riyanto (2008:57) mengemukakan bahwa modal kerja terbagi menjadi tiga konsep yaitu :

\section{1) Konsep Kuantitatif}

Modal kerja menurut konsep ini adalah keseluruhan dari jumlah aktiva lancar atau disebut juga dengan modal kerja bruto (gross working capital).
2) Konsep Kualitatif

Modal kerja menurut konsep ini adalah sebagian dari aktiva lancar yang benar-benar dapat digunakan untuk membiayai operasional perusahaan tanpa mengganggu likuiditasnya yaitu yang merupakan kelebihan dari aktiva lancar diatas utang lancarnya. Modal kerja konsep ini disebut modal kerja neto (net working capital).

\section{3) Konsep Fungsionil}

Konsep ini mendasarkan pada fungsi dari dana dalam menghasilkan pendapatan (income). Setiap dana yang digunakan dalam perusahaan dimaksudkan untuk menghasilkan pendapatan.

Dari ketiga konsep yang telah dikemukakan pada penelitian ini akan menggunakan konsep kuantitatif di mana modal kerja merupakan keseluruhan dari aktiva lancar.

Efektivitas secara

umum merupakan kemampuan yang dimiliki perusahaan untuk mengendalikan modal kerja dengan baik dan sesuai dengan tujuan yang telah ditetapkan sebelumnya oleh perusahaan. Adapun pengertian efektivitas menurut beberapa pendapat di antaranya yaitu:

Menurut Kurniawan (2005:109) dalam Arrin Prastiwi, Widiarti Putri, Moch. Dzukirom AR., Muhammad Saifi (2016:2) :

"Efektivitas adalah kemampuan melaksanakan tugas, fungsi 'operasi kegiatan program atau misi' dari pada suatu organisasi atau sejenisnya yang tidak adanya tekanan atau ketegangan di antara pelaksanaannya".

Berdasarkan pengertianpengertian efektivitas menurut beberapa pendapat dapat disimpulkan bahwa efektivitas menunjukkan tingkat keberhasilan dari suatu perusahaan 
atau koperasi dalam mencapai tujuan yang telah ditentukan. Semakin mendekati hasil yang diharapkan maka efektivitasnya semakin tinggi. Sehingga hasil yang didapatkan tersebut dapat dikatakan efektif.

Menurut Fred Weston dalam Kasmir (2010:110) mengartikan rasio likuiditas merupakan rasio yang menggambarkan kemampuan perusahaan memenuhi kewajiban (utang) jangka pendek.

Berdasarkan uraian beberapa pengertian tersebut menunjukkan bahwa rasio likuiditas merupakan rasio untuk menunjukkan kemampuan perusahaan maupun koperasi dalam memenuhi kewajiban jangka pendek yang harus segera dipenuhi.

Pengukuran rasio likuiditas menurut Agus Harjito dan Martono (2011:55-56) menyajikan dua macam likuiditas di antaranya yaitu :

\section{1) Current Ratio (Rasio Lancar)}

Rasio lancar merupakan perbandingan antara aktiva lancar dengan hutang lancar. Rasio lancar yang tinggi memberikan indikasi jaminan yang baik bagi kreditur jangka pendek dalam arti setiap saat perusahaan memiliki kemampuan untuk melunasi kewajiban-kewajiban finansial jangka pendeknya. Akan tetapi jika rasio lancar terlalu tinggi akan berpengaruh terhadap kemampuan memperoleh laba, karena sebagian modal kerja tidak berputar atau mengalami pengangguran. Berikut ini rumus pengukuran current ratio:

$$
\text { Current Ratio }=\frac{\text { Aktiva Lancar }}{\text { Utang Lancar }}
$$

\section{2) Quick Ratio (Rasio Cepat) \\ Rasio ini merupakan} perimbangan antara jumlah aktiva lancar yang dikurangi persediaan dengan jumlah hutang lancar. Rasio cepat memfokuskan pada komponen aktiva lancar yang lebih likuid. Berikut ini rumus pengukuran quick ratio:

Quick Ratio $=\frac{\text { Aktiva Lancar }- \text { Persediaan }}{\text { Utang Lancar }}$

Dalam penelitian ini likuiditas dihitung menggunakan Current Ratio yaitu dengan membandingkan aktiva lancar dengan hutang lancar.

\section{A. Metode Penelitian}

Dalam penelitian ini metode yang digunakan adalah metode studi kasus, dengan pendekatan kuantitatif yang bersifat deskriptif. Melalui pengukuran efektivitas penggunaan modal kerja dalam upaya meningkatkan likuiditas pada masing-masing Unit Usaha KSU Karya Nugraha Jaya Kab. Kuningan, sehingga diharapkan dapat menyelesaikan permasalahan koperasi. Menggunakan data kualitatif dan kuantitatif yang diperoleh dari informan melalui wawancara serta kajian pustaka dari dokumen koperasi.

\section{Analisis Data:}

Dari data yang telah dikumpulkan maka peneliti akan melakukan analisis dan identifikasi untuk menjawab permasalahan yang ada sebagai berikut

1. Untuk menjawab identifikasi masalah yang pertama dilakukan dengan cara menghitung rasio perputaran modal kerja, di mana pada penelitian ini modal kerja yang akan digunakan adalah modal kerja yang berasal dari seluruh aktiva lancar masing-masing unit usaha, aktiva lancar ini tersusun dari elemen-elemen di antaranya kas dan bank, piutang, serta persediaan. Perhitungan rasio-rasio tersebut dapat dihitung dengan 


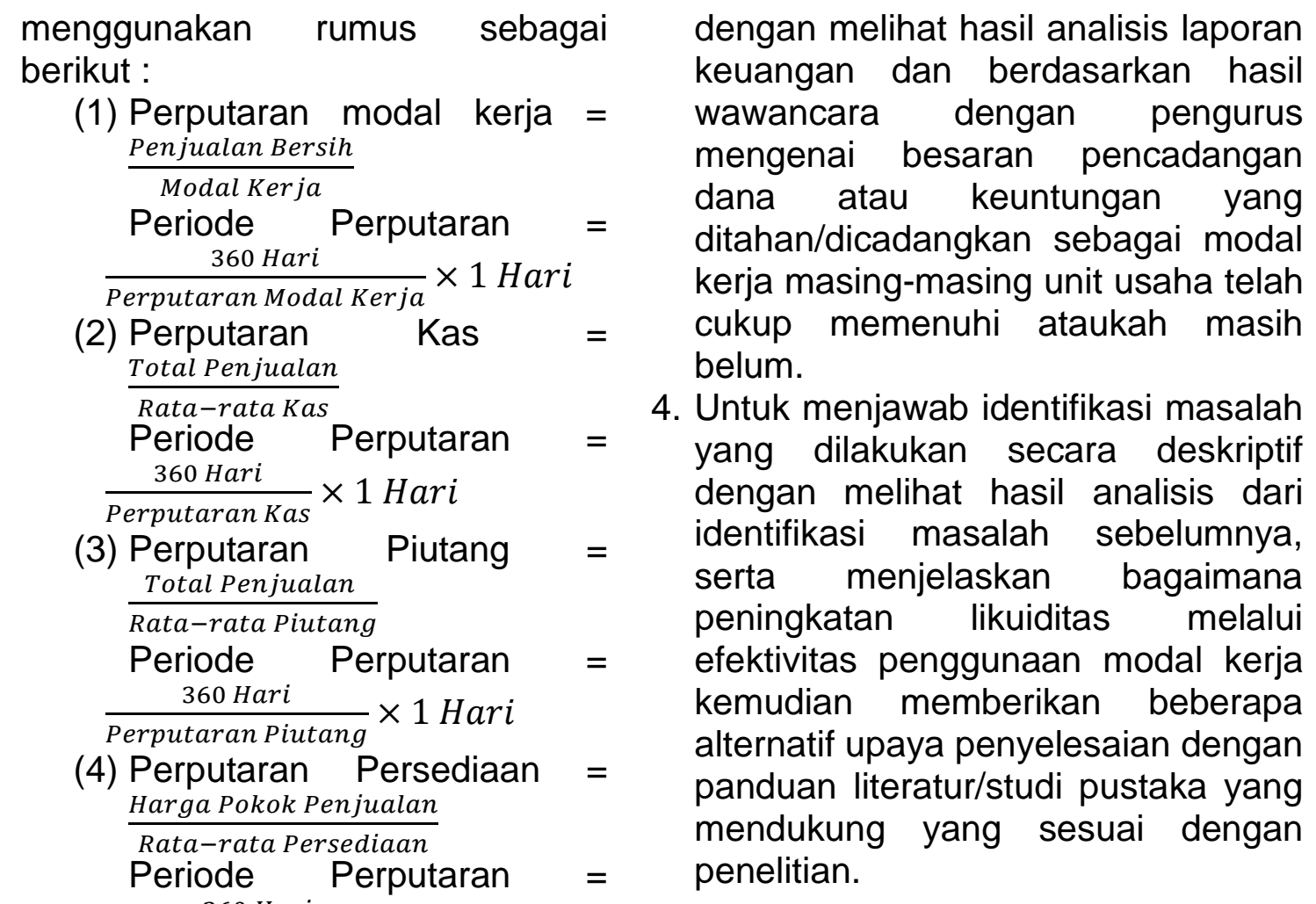
$\frac{360 \text { Hari }}{\text { Perputaran Persediaan }} \times 1$ Hari

Kriteria penilaian efektif tidaknya dapat dianalisis dari sudah tercapai atau belum target yang diharapkan koperasi serta apabila tingkat perputaran semakin tinggi maka modal kerja dapat dikatakan semakin efektif. Sebaliknya apabila perputaran semakin rendah maka modal kerja dapat dikatakan semakin tidak efektif.

2. Untuk menjawab identifikasi masalah yang kedua akan dijawab dengan cara perhitungan rasio likuiditas dengan perhitungan rasio lancar (current ratio) masing-masing unit usaha yang kemudian akan dianalisis dengan mengacu kepada Peraturan Menteri Negara Koperasi dan UKM Republik Indonesia No.06/Per/M/KUKM/V/2006 Tentang Pedoman Penilaian Koperasi Berprestasi.

3. Untuk menjawab identifikasi masalah yang dilakukan secara deskriptif

\section{PEMBAHASAN}

\section{Hasil Penelitian}

\section{Efektivitas Penggunaan Modal} Kerja Masing-masing Unit Usaha di KSU Karya Nugraha Jaya

\section{Kab.Kuningan}

Efektivitas adalah sebuah ukuran yang dapat menyatakan seberapa baik pencapaian target secara kuantitas, kualitas maupun waktu yang telah dicapai oleh koperasi. Di mana semakin tinggi persentase pencapaian target, maka semakin baik efektivitasnya.

Efektivitas secara umum merupakan kemampuan yang dimiliki perusahaan untuk mengendalikan modal kerja dengan baik dan sesuai dengan tujuan yang telah ditetapkan sebelumnya oleh perusahaan maupun koperasi.

Tabel 2.1. Target Efektivitas Penggunaan Modal Kerja KSU Karya Nugraha Jaya Kab. Kuningan 


\begin{tabular}{|c|c|c|c|c|c|}
\hline \multicolumn{2}{|c|}{$\begin{array}{c}\text { Unit Usaha } \\
\text { Susu dan } \\
\text { Unit Usaha } \\
\text { Pakan, } \\
\text { Barang }\end{array}$} & \multicolumn{2}{|c|}{$\begin{array}{l}\text { Unit Usaha } \\
\text { Peternakan }\end{array}$} & \multicolumn{2}{|c|}{$\begin{array}{l}\text { Unit Usaha } \\
\text { Simpan } \\
\text { Pinjam dan } \\
\text { PKPS }\end{array}$} \\
\hline $\begin{array}{l}\text { Stan } \\
\text { dar }\end{array}$ & $\begin{array}{c}\text { Ketera } \\
\text { ngan }\end{array}$ & $\begin{array}{c}\text { Stan } \\
\text { dar }\end{array}$ & $\begin{array}{c}\text { Ketera } \\
\text { ngan }\end{array}$ & $\begin{array}{c}\text { Stan } \\
\text { dar }\end{array}$ & $\begin{array}{c}\text { Ketera } \\
\text { ngan }\end{array}$ \\
\hline $\begin{array}{l}\geq 8 \\
\text { Kali }\end{array}$ & Efektif & $\begin{array}{l}\geq 1 \\
\text { Kali }\end{array}$ & Efektif & $\begin{array}{l}\geq 1 \\
\text { Kali }\end{array}$ & Efektif \\
\hline $\begin{array}{l}<8 \\
\text { Kali }\end{array}$ & $\begin{array}{l}\text { Tidak } \\
\text { Efektif }\end{array}$ & $\begin{array}{l}<1 \\
\text { Kali }\end{array}$ & $\begin{array}{l}\text { Tidak } \\
\text { Efektif }\end{array}$ & $\begin{array}{l}<1 \\
\text { Kali }\end{array}$ & $\begin{array}{l}\text { Tidak } \\
\text { Efektif }\end{array}$ \\
\hline
\end{tabular}

Sumber: Data diolah.

KSU Karya Nugraha Jaya menetapkan minimal waktu proses berputarnya modal kerja untuk kembali lagi menjadi kas pada unit usaha susu dan unit usaha pakan dan barang disesuaikan dengan rencana penjualan yang ditetapkan koperasi pada tahun 2020 adalah sebanyak 8 kali atau lebih dari 8 kali dalam setahun artinya penggunaan modal kerja optimal dengan sisa hasil usaha paling menguntungkan pada unit usaha susu dan unit usaha pakan dan barang. Kemudian menetapkan minimal waktu proses berputarnya modal kerja untuk kembali lagi menjadi kas pada unit usaha peternakan selama 1 kali atau lebih dari 1 kali dalam setahun. Kemudian pada menetapkan minimal waktu proses berputarnya modal kerja untuk kembali lagi menjadi kas pada unit usaha simpan pinjam dan PKPS (Program Kredit Pembelian Sapi) selama 1 kali atau lebih dari 1 kali dalam setahun. Pada tiga unit usaha tersebut apabila kurang dari waktu yang ditentukan pada masing-masing unit usaha maka dapat dikatakan perputaran modal kerjanya tidak efektif. Adapun perkembangan efektivitas penggunaan modal kerja masing-masing unit usaha pada KSU Karya Nugraha Jaya Kab. Kuningan adalah sebagai berikut:

Tabel 2.2. Efektivitas Penggunaan Modal Kerja Masing-masing Unit Usaha Pada KSU Karya Nugraha Jaya Kab. Kuningan

\begin{tabular}{|c|c|c|c|c|}
\hline \multirow[b]{2}{*}{$\begin{array}{l}\text { Unit } \\
\text { Usaha }\end{array}$} & \multicolumn{3}{|c|}{$\begin{array}{c}\text { Perputaran Modal } \\
\text { Kerja }\end{array}$} & \multirow[b]{2}{*}{$\begin{array}{c}\text { Keteranga } \\
n\end{array}$} \\
\hline & $\begin{array}{c}2018 \\
\text { (Kali } \\
\text { ) }\end{array}$ & $\begin{array}{c}2019 \\
\text { (Kali } \\
\text { ) }\end{array}$ & $\begin{array}{l}2020 \\
\text { (Kali } \\
\text { ) }\end{array}$ & \\
\hline $\begin{array}{l}\text { Produksi } \\
\text { Susu, } \\
\text { Pakan dan } \\
\text { Barang }\end{array}$ & 9,49 & 8,64 & 7,72 & $\begin{array}{l}\text { Tidak } \\
\text { Efektif }\end{array}$ \\
\hline $\begin{array}{l}\text { Peternaka } \\
\mathrm{n}\end{array}$ & 0,61 & 0,62 & 0,67 & $\begin{array}{l}\text { Tidak } \\
\text { Efektif }\end{array}$ \\
\hline $\begin{array}{l}\text { Simpan } \\
\text { Pinjam } \\
\text { dan PKPS }\end{array}$ & 0,14 & 0,13 & 0,10 & $\begin{array}{l}\text { Tidak } \\
\text { Efektif }\end{array}$ \\
\hline
\end{tabular}

Sumber: Data diolah.

Dari Tabel 2.2 di atas dapat disimpulkan bahwa dari tiga unit usaha pada KSU Karya Nugraha Jaya Kab.Kuningan yaitu (1) unit usaha susu, dan unit usaha pakan dan barang, (2) unit usaha peternakan, serta (3) unit usaha simpan pinjam dan PKPS penggunaan modal kerjanya belum efektif sesuai target yang diharapkan koperasi.

\section{Likuiditas Masing-masing Unit Usaha di KSU Karya Nugraha Jaya Kab.Kuningan}

Likuiditas merupakan ukuran yang dapat digunakan untuk melihat tingkat kemampuan koperasi dalam membayar kewajibannya pada saat waktu jatuh tempo pembayaran. Apabila likuiditas koperasi sangat baik maka koperasi mampu membayar kewajiban jangka pendek tepat pada waktunya tanpa mengalami kesulitan keuangan.

Adapun standar penilaian likuiditas (current ratio) menurut Peraturan Menteri Negara Koperasi dan UKM Republik Indonesia No.06/Per/M/KUKM/V/2006 Tentang Pedoman Penilaian Koperasi Berprestasi, adalah sebagai berikut : 
EFEKTIVITAS PENGGUNAAN MODAL KERJA DALAM UPAYA MENINGKATKAN LIKUIDITAS MASING-MASING UNIT USAHA KSU KARYA NUGRAHA JAYA KABUPATEN KUNINGAN

Tabel 2.3. Standar Penilaian Likuiditas (Current Ratio)

\begin{tabular}{|c|c|}
\hline Kriteria & Interval \\
\hline Sangat Baik & $200 \%$ s $/ \mathrm{d} 250 \%$ \\
\hline Baik & $\begin{array}{c}175 \% \text { s } / d<200 \% \\
\text { atau }>250 \% \text { s/d } \\
275 \%\end{array}$ \\
\hline Cukup Baik & $\begin{array}{c}150 \% \text { s } / d<175 \% \\
\text { atau }>275 \% \text { s/d } \\
300 \%\end{array}$ \\
\hline Kurang Baik & $\begin{array}{c}125 \% \mathrm{~s} / \mathrm{d}<150 \% \\
\text { atau }>300 \% \mathrm{~s} / \mathrm{d} \\
325 \%\end{array}$ \\
\hline Buruk & $<125 \%$ atau $>325 \%$ \\
\hline
\end{tabular}

Sumber: Peraturan Menteri Negara Koperasi dan UKM Republik Indonesia No.06/Per/M/KUKM/V/2006 Tentang pedoman penilaian koperasi berprestasi.

Tabel 2.4. Likuiditas (current ratio) Masingmasing Unit Usaha Pada KSU Karya Nugraha Jaya Kab. Kuningan

\begin{tabular}{|c|c|c|c|c|}
\hline \multirow{2}{*}{$\begin{array}{l}\text { Unit } \\
\text { Usaha }\end{array}$} & \multicolumn{3}{|c|}{$\begin{array}{c}\text { Likuiditas (current } \\
\text { ratio) }\end{array}$} & \multirow{2}{*}{$\underset{\mathrm{ri}}{\text { Katego }}$} \\
\hline & $\begin{array}{c}2018 \\
(\%)\end{array}$ & $\begin{array}{c}2019 \\
(\%)\end{array}$ & $\begin{array}{c}2020 \\
(\%)\end{array}$ & \\
\hline $\begin{array}{l}\text { Produksi } \\
\text { Susu, } \\
\text { Pakan } \\
\text { dan } \\
\text { Barang }\end{array}$ & $\begin{array}{c}106,1 \\
6\end{array}$ & $\begin{array}{c}124,4 \\
9\end{array}$ & $\begin{array}{c}130,7 \\
8\end{array}$ & $\begin{array}{c}\text { Kurang } \\
\text { Baik }\end{array}$ \\
\hline $\begin{array}{l}\text { Peternak } \\
\text { an }\end{array}$ & $\begin{array}{c}102,5 \\
9\end{array}$ & $\begin{array}{c}105,7 \\
4\end{array}$ & $\begin{array}{c}105,6 \\
5\end{array}$ & Buruk \\
\hline $\begin{array}{l}\text { Simpan } \\
\text { Pinjam } \\
\text { dan } \\
\text { PKPS }\end{array}$ & $\begin{array}{c}130,1 \\
1\end{array}$ & $\begin{array}{c}139,6 \\
1\end{array}$ & $\begin{array}{c}156,6 \\
0\end{array}$ & $\begin{array}{l}\text { Cukup } \\
\text { Baik }\end{array}$ \\
\hline
\end{tabular}

Sumber: Data diolah.

Dari Tabel 2.4 di atas dapat disimpulkan bahwa likuiditas dari tiga unit usaha pada KSU Karya Nugraha Jaya Kab. Kuningan apabila mengacu pada Peraturan Menteri Negara Koperasi dan UKM Republik Indonesia No.06/Per/M/KUKM/V/2006 Tentang pedoman penilaian koperasi berprestasi yaitu pada (1) unit usaha susu, dan unit usaha pakan dan barang masuk dalam kategori kurang baik, (2) unit usaha peternakan masuk dalam kategori buruk, serta (3) unit usaha simpan pinjam dan PKPS masuk dalam kategori cukup baik.

\section{Pencadangan Dana Masing- masing Unit Usaha di KSU Karya Nugraha Jaya Kab.Kuningan Unit Usaha Susu dan Unit Usaha Pakan dan Barang}

Tabel 2.5. Perkembangan Dana Cadangan Unit Usaha Susu Unit Usaha Pakan dan Barang KSU Karya Nugraha Jaya Kab. Kuningan Tahun 2018-2020

\begin{tabular}{|c|c|c|c|}
\hline Tahun & $\begin{array}{c}\text { Sisa Hasil Usaha } \\
(\mathrm{Rp})\end{array}$ & $\begin{array}{c}\text { Penyisihan Dana } \\
\text { Cadangan 20\% } \\
(\mathrm{Rp})\end{array}$ & $\begin{array}{c}\mathrm{N} / \mathrm{T} \\
(\%)\end{array}$ \\
\hline 2018 & $1.584 .430 .734,46$ & $316.886 .146,89$ & - \\
\hline 2019 & $1.709 .936 .269,11$ & $341.987 .253,82$ & 7,92 \\
\hline 2020 & $1.854 .717 .318,77$ & $370.943 .463,76$ & 8,47 \\
\hline
\end{tabular}

Sumber: Laporan Rapat Anggota Tahunan KSU Karya Nugraha Jaya Kab. Kuningan Tahun 2018-2020

Berdasarkan Tabel 2.5 menunjukkan penyisihan dana cadangan sebesar $20 \%$ pada unit usaha susu dan unit usaha pakan dan barang mengalami peningkatan. Artinya dana yang dicadangkan cukup dalam memenuhi kebutuhan operasional usaha.

\section{Unit Usaha Peternakan}

Tabel 2.6. Nugraha Jaya Kab. Kuningan Tahun 2018-2020

\begin{tabular}{|c|c|c|c|}
\hline Tahun & $\begin{array}{c}\text { Sisa Hasil } \\
\text { Usaha (Rp) }\end{array}$ & $\begin{array}{c}\text { Penyisihan Dana } \\
\text { Cadangan 20\% } \\
\text { (Rp) }\end{array}$ & $\mathrm{N} / \mathrm{T}(\%)$ \\
\hline 2018 & $35.395 .190,00$ & $7.079 .038,00$ & - \\
\hline 2019 & $26.239 .950,00$ & $5.247 .990,00$ & $(25,87)$ \\
\hline 2020 & $(22.818 .970,00)$ & $(4.563 .794,00)$ & $(186,96)$ \\
\hline
\end{tabular}


Sumber: Laporan Rapat Anggota Tahunan KSU Karya Nugraha Jaya Kab. Kuningan Tahun 2018-2020

Berdasarkan Tabel 2.6 menunjukkan penyisihan dana cadangan sebesar $20 \%$ pada unit usaha peternakan mengalami penurunan selama tiga tahun terakhir dan pada tahun 2020 mengalami kerugian sebesar Rp.22.818.970,00 menunjukkan bahwa cadangan dana tersebut belum atau tidak cukup untuk memenuhi kegiatan operasional usaha pada unit peternakan.

\section{Unit Usaha Simpan Pinjam dan PKPS}

Tabel 2.7 Perkembangan Dana Cadangan Unit Usaha Simpan Pinjam dan PKPS KSU Karya Nugraha Jaya Kab. Kuningan Tahun 2018-2020

\begin{tabular}{|c|c|c|c|}
\hline $\begin{array}{c}\text { Tahu } \\
\mathrm{n}\end{array}$ & $\begin{array}{l}\text { Sisa Hasil } \\
\text { Usaha (Rp) }\end{array}$ & $\begin{array}{l}\text { Penyisihan } \\
\text { Dana } \\
\text { Cadangan } \\
20 \%(R p)\end{array}$ & $\begin{array}{l}\mathrm{N} / \mathrm{T} \\
(\%)\end{array}$ \\
\hline 2018 & $\begin{array}{c}60.112 .233,0 \\
0\end{array}$ & $12.022 .446,60$ & - \\
\hline 2019 & $\begin{array}{c}54.614 .563,2 \\
0\end{array}$ & $\begin{array}{c}10.922 .912 ., 6 \\
4\end{array}$ & $(9,15)$ \\
\hline 2020 & $\begin{array}{c}45.223 .137,0 \\
0\end{array}$ & $9.044 .627,40$ & $\begin{array}{c}(17,20 \\
)\end{array}$ \\
\hline
\end{tabular}

Sumber: Laporan Rapat Anggota Tahunan KSU Karya Nugraha Jaya Kab. Kuningan Tahun 2018-2020

$\begin{array}{ll}\text { Berdasarkan } & \text { Tabel } \\ 2.7\end{array}$ menunjukkan penyisihan dana cadangan sebesar $20 \%$ pada unit usaha simpan pinjam dan PKPS mengalami penurunan selama tiga tahun terakhir. Dilihat dari sisa hasil usaha yang masih dapat diperoleh unit usaha menunjukkan cadangan dana tersebut cukup untuk memenuhi kegiatan operasional usaha namun modal kerja belum berputar secara optimal.
3. Upaya Meningkatkan Likuiditas Masing-masing Unit Usaha di KSU Karya Nugraha Jaya Kab.Kuningan Melalui Efektivitas Penggunaan Modal Kerja

1) Pada unit usaha susu dan unit usaha pakan dan barang meningkatkan likuiditas melalui efektivitas penggunaan modal kerja dengan meningkatkan perputaran modal kerja dengan begitu penjualan akan meningkat, kemudian sisa hasil usaha bertambah dan akan menambah dana cadangan untuk menambah modal kerja.

2) Pada unit usaha peternakan meningkatkan likuiditas pada unit usaha yang mengalami kerugian bisa melalui efektivitas penggunaan modal kerja dengan meningkatkan simpanan wajib anggota dengan cara : menambah populasi sapi anggota sehingga produktivitas meningkat dan bisa meningkatkan simpanan wajib anggota yang jumlahnya dipotong $15 \%$ dari penjualan susu sapi kepada koperasi dengan alternatif ini koperasi dapat menutupi hutang atau kerugian yang ada. Atau dengan menambah modal kerja lewat program LPDB.

3) Pada unit usaha simpan pinjam dan PKPS meningkatkan modal kerjanya dengan mengikuti program LPDB KUMKM (Lembaga Pengelola Dana Bergulir Koperasi dan Usaha Mikro, Kecil dan Menengah) dengan berusaha memperoleh dana hibah atau dana pinjaman pada LPDB dengan suku bunga rendah dengan dana tersebut dapat digunakan untuk 
menambah modal kerja pada aktiva lancar sehingga likuiditas meningkat.

\section{KESIMPULAN DAN SARAN Kesimpulan:}

1. Efektivitas penggunaan modal kerja pada tiga unit usaha di KSU KNJ tidak mencapai target sehingga tidak efektif.

2. (1)Likuiditas pada unit usaha susu dan unit usaha pakan dan barang dalam kategori kurang baik. (2) Likuiditas pada unit usaha dalam kategori buruk. (3) Likuiditas pada unit usaha simpan pinjam dan PKPS dalam kategori cukup baik.

3. Dana cadangan pada tiga unit usaha di KSU hanya pada unit usaha peternakan yang belum mencukupi sisanya telah mencukupi.

4. (1) pada unit usaha susu dan unit usaha pakan dan barang upaya meningkatkan likuiditas melalui penambahan dana cadangan dengan meningkatkan perputaran modal kerja (2) pada unit usaha peternakan yang mengalami kerugian upaya meningkatkan likuiditas selain lewat dana cadangan bisa dengan penambahan simpanan wajib anggota, serta mengikuti program LPDB untuk memperoleh tambahan modal kerja(3) pada unit usaha simpan pinjam dan PKPS upaya meningkatkan likuiditas penambahan dana cadangan, atau dengan memperoleh pinjaman jangka panjang dari LPDB KUMKM (Lembaga Pengelola Dana Bergulir Koperasi dan Usaha Mikro, Kecil dan Menengah) dengan bunga yang rendah

\section{Saran:}

1. Meningkatkan penggunaan dengan efektivitas modal kerja perputaran modal kerja melalui peningkatan penjualan. (1) pada unit usaha susu dapat menambah jumlah populasi sapi untuk meningkatkan produktivitas. Kemudian pada unit usaha pakan dan barang peningkatan penjualan dapat melalui penyuluhan kepada anggota bahwa produk lebih baik dan berkualitas serta memberi bonus pada anggota yang sering membeli produk di koperasi sebagai promosi. (2) pada unit usaha peternakan penjualan dapat ditingkatkan dengan menciptakan sumber pendapatan baru seperti pemanfaatan limbah kotoran sapi dikembangkan menjadi pupuk organik atau bahan bakar organik (biogas). (3) Pada unit usaha simpan pinjam dan PKPS meningkatkan pendapatan dengan pembaharuan sistem pembayaran langsung tanpa harus menjual susu yang diperuntukkan bagi anggota dengan keadaan sapi masa laktasi (baru melahirkan).

2. Memperbaiki likuiditas current ratio pada masing-masing unit usaha dengan cara (1) Unit susu dan unit usaha pakan dan barang dengan menambah modal kerja dari dana yang dicadangkan ditanamkan pada aktiva lancar bertambah dan likuiditas meningkat. (2) unit usaha peternakan dapat menambah modal kerja melalui 
peningkatan simpanan wajib anggota dengan adanya penambahan populasi sapi. (3)unit usaha simpan pinjam dan PKPS menambah modal kerja dengan memperoleh hutang jangka panjang dengan bunga yang rendah.

3. Untuk menutupi dana cadangan yang tidak mencukupi pada unit usaha peternakan koperasi dapat meningkatkan persentase dana cadangan serta mengoptimalkan pengeluaran biaya operasional, menambah simpanan wajib anggota, dan tambahan dana dari pinjaman jangka panjang.

4. Koperasi dapat membuat rencana penggunaan modal kerja yang baik dengan membuat target pendapatan yang seharusnya pada setiap unit usaha dengan mempertimbangkan pengoptimalan anggaran biaya yang akan dikeluarkan agar tidak terjadi kerugian pada unit usaha yang akan merugikan koperasi juga.

\section{DAFTAR PUSTAKA}

Ami Purnamawati, \& Rusidi. (2015). Metodelogi Penelitian, Sistematika Usulan Penelitian dan Skripsi. Bandung: IKOPIN.

Bambang Riyanto. (2008). Dasar-Dasar Pembelanjaaan Perusahaan. Yogyakarta: BPFE.

D. Agus Harjito, \& Martono. (2011). Manajemen Keuangan. Yogyakarta: EKONISIA.

Hendar. (2010). Manajemen Perusahaan Koperasi. Jakarta: Erlangga.

Kasmir. (2010). Pengantar Manajemen Keuangan. Jakarta: Kencana.
Laporan Pertanggungjawaban Pengurus dan Pengawas Koperasi Serba Usaha Karya Nugraha Jaya Kabupaten Kuningan Tahun Buku 2018.

Laporan Pertanggungjawaban Pengurus dan Pengawas Koperasi Serba Usaha Karya Nugraha Jaya Kabupaten Kuningan Tahun Buku 2019.

Laporan Pertanggungjawaban Pengurus dan Pengawas Koperasi Serba Usaha Karya Nugraha Jaya Kabupaten Kuningan Tahun Buku 2020.

Lukman Syamsuddin. (2004). Manajemen Keuangan Perusahaan. Jakarta: Grafindo.

Munawir. (2014). Analisa Laporan Keuangan. Yogyakarta: Liberty.

Peraturan Menteri Negara Koperasi dan Usaha Kecil Menengah Republik Indonesia. Nomor 06/Per/M.KUKM/2006. Tentang Pedoman Penilaian Koperasi Berprestasi, Koperasi Award (2006). Ramudi Arifin. (2013). Koperasi Sebagai Perusahaan. Bandung: IKOPIN Press.

Sitio, A, \& Halomoan Tamba. (2001). Koperasi Teori dan Praktik. Jakarta: Erlangga.

Undang-Undang Nomor 25 tahun 1992 Tentang Perkoperasian.(2011). Bandung: Citra Umbara

Jurnal :

Arrin Prastiwi Widiarti Putri, Moch. Dzukirom AR, dan Muhammad Saifi (2016). Efektivitas Penggunaan Modal Kerja Sebagai Salah Satu Upaya Meningkatkan Likuiditas (Studi Kasus Pada Perusahaan 
EFEKTIVITAS PENGGUNAAN MODAL KERJA DALAM UPAYA MENINGKATKAN LIKUIDITAS MASING-MASING UNIT USAHA KSU KARYA NUGRAHA JAYA KABUPATEN KUNINGAN

Indomobil Sukses Internasional Tbk

Tahun 2012-2014). Administrasi

Bisnis 54-62

Rahman Jauhari dan Ridwan (2017).

Efesiensi dan Efektivitas

Penggunaan Modal Kerja Pada

Koperasi Syariah di Kota Banda

Aceh Tahun 2011-2015. Ekonomi

Akuntansi 168-179 